\title{
Influence of a low-frequency alternating magnetic field on hot tearing susceptibility of $\mathrm{EV} 31$ magnesium alloy
}

\author{
Xin Su ${ }^{1,2}$, Zhi-jun Feng ${ }^{3}$, Jing-fu Huang ${ }^{2}$, Xu-dong Du', Ru-shuang An ${ }^{1,2}$, **Feng Wang ${ }^{4},{ }^{*}$ Yan-chun Lou ${ }^{1}$ \\ 1. State Key Laboratory of Light Alloy Casting Technology for High-end Equipment, Shenyang 110022, China \\ 2. Shenyang Research Institute of Foundry Co., Ltd., Shenyang 110022, China \\ 3. Shenyang Research Casting Technology Co., Ltd., Shenyang 110141, China \\ 4. College of Materials Science and Engineering, Shenyang University of Technology, Shenyang 110870, China
}

\begin{abstract}
The effect of a low-frequency alternating magnetic field (AMF, 0 A $0 \mathrm{~Hz}, 5 \mathrm{~A} 10 \mathrm{~Hz}, 10 \mathrm{~A} 10 \mathrm{~Hz}, 15 \mathrm{~A}$ $10 \mathrm{~Hz}$ ) on the hot tearing susceptibility (HTS) of a magnesium alloy (EV31) was systematically studied using a combination of experiment and numerical simulation. By observing the macroscopic hot cracks in hot joints of the "T" samples, the hot tearing tendency of the samples was analyzed. The HTS of the alloy can be predicted via numerical simulation and the crack susceptibility coefficient (CSC). The microstructure and morphology of the hot tearing zone of EV31 were investigated using scanning electron microscopy (SEM). Results show that increasing the magnetic field strength reduces both the alloy solidification temperature range and the dendrite coherency temperature, which increases the feeding time during solidification and decreases the HTS of the alloy. When the magnetic field parameters are $10 \mathrm{~Hz} 15 \mathrm{~A}$, the EV31 alloy shows the lowest HTS. The main component of the second phase in the microstructure is $\mathrm{Mg}_{12} \mathrm{Nd}$. This study also found that the electromagnetic field can effectively refine the grains, purify the melt, and reduce the oxide content in the melt. The obtained simulation results are consistent with the experimental results.
\end{abstract}

Key words: EV31 magnesium alloy; electromagnetic field; hot tearing susceptibility; microstructure; dendrite coherency temperature
CLC numbers: TG146.22
Document code: A
Article ID: 1672-6421(2021)03-229-10

\section{Introduction}

Magnesium alloy, as the lightest metallic structural material at present, is widely used in areas such as aerospace engineering, transport, and computer production. Magnesium alloy is also known as the $21^{\text {st }}$ century's green engineering material because of its low density, high specific strength, high specific rigidity, good cuttability, excellent damping/vibrationreduction properties, good formability, easy casting, and suitability for hot processing ${ }^{[1-3]}$. However, due to its

\section{*Yan-chun Lou}

Male, Ph. D, Researcher. He is the Vice General Manager of the China Academy of Machinery Science and Technology Group Co., Ltd. He has won two National Prizes for Progress in Science and Technology (both in second place). His research interests mainly focus on the R\&D of foundry materials, casting technology and equipment, and their engineering application.

E-mail: louych@chinasrif.com

**Feng Wang

E-mail:wf9709@126.com

Received: 2021-01-21; Accepted: 2021-05-22 wide temperature range for solidification and its great solidification shrinkage, magnesium alloys are generally prone to hot tearing during the casting process ${ }^{[4]}$. Magnesium alloy products are becoming increasingly thin-walled and complicated, the occurrence of hot tearing has become one of the bottlenecks that restrict broader commercial application ${ }^{[5]}$.

Addition of proper rare earth elements can refine the grain and reduce the hot tearing susceptibility (HTS) of the cast magnesium alloy. However, when the content of rare earth elements in the alloy is too high, the solidification temperature range of the alloy becomes larger and the HTS of the alloy increases ${ }^{[6]}$. In recent years, the alloy EV31 has drawn increasing attention in aerospace and biomedical R\&D due to its strong solution strengthening and precipitation strengthening characteristics as well as its good creep resistance and corrosion resistance ${ }^{[7,8]}$. However, EV31 contains more rare earth elements, leading to a large solidification temperature range and high HTS. In addition, there are few studies that focus on the HTS of EV31.

Refining the alloy structure can effectively reduce 
the HTS of the alloy. The methods of refining the alloy structure mainly include alloying, refining, mechanical stirring, electromagnetic stirring and so on. Compared with other refinement processes, the greatest features and advantages of electromagnetic stirring are that it does not cause environmental pollution, and it is possible to avoid direct contact with the molten metal. During the melting process, an electromagnetic-field treatment can purify the alloy melt, improve the alloy structure, and reduce the HTS of alloy ${ }^{[9]}$. El-Kaddah et al. ${ }^{[10]}$ verified experimentally that electromagnetic force could effectively separate inclusions by using the difference of conductivity between inclusions and melts. Research by Li et al. ${ }^{[1]}$ on the purification effect of an electromagnetic field on magnesium-alloy melt showed that most impurity atoms in the melt accumulated near the edge of melt under the action of magnetic field. Currently, research concerning the effect of the magnetic field on the HTS of magnesium alloy has become a hot spot. Du et al. ${ }^{[12]}$ found that, under a low-frequency alternating magnetic field, with increasing magnetic field frequency, the HTS of AXJ530 alloy decreased firstly and then increased. The HTS of AXJ530 alloy at different magnetic field frequency was ranked as follows: $10 \mathrm{~A}, 10 \mathrm{~Hz}<10 \mathrm{~A}, 15 \mathrm{~Hz}<10 \mathrm{~A}, 5 \mathrm{~Hz}<0 \mathrm{~A}, 0 \mathrm{~Hz}$. Zhou et al. ${ }^{[13]}$ indicated that, under the effect of $0.03 \mathrm{~T}$ magnetic field, forced convection increased the number of free particles, promoted the formation of crystal nuclei, inhibited the formation and growth of dendrites, formed a uniform and fine-grained structure, and reduced the HTS of $\mathrm{Mg}-7 \mathrm{Zn}-x \mathrm{Cu}-0.6 \mathrm{Zr}$ alloy. Furthermore, research by Zhang et al. ${ }^{[14]}$ showed that, with low-frequency electromagnetic casting, the microstructure of the billets was significantly refined, and the HTS of ZK60 magnesium alloy billets could be reduced significantly.

This experiment explored the influence of magnetic field on the HTS of EV31 alloy by combining numerical simulation with experiments. By changing the magnetic field strength (0 A $0 \mathrm{~Hz}, 5 \mathrm{~A} 10 \mathrm{~Hz}, 10 \mathrm{~A} 10 \mathrm{~Hz}, 15 \mathrm{~A} 10 \mathrm{~Hz}$ ), the HTS of EV3 was studied. This study aims to offer a theoretical basis to develop related alloy-based applications in engineering.

\section{Experimental procedure}

\subsection{Experimental materials and process}

Commercial magnesium alloy EV31 was used, and the chemical composition is shown in Table 1. The hot tearing experiment was performed on a "T-shaped" hot tearing mold with a solidification shrinkage force acquisition system, as shown in Fig. $1^{[12]}$. The device mainly consists of a hot tearing testing system, a load sensor, a magnetic field system, and a data-acquisition system. In this experiment, the effect of a lowfrequency alternating magnetic field of $10 \mathrm{~Hz}$ on the HTS of the EV31 magnesium alloy was studied, and the currents used were $5 \mathrm{~A}, 10 \mathrm{~A}$, and $15 \mathrm{~A}$, respectively. During the experiment, $550 \mathrm{~g}$ of EV31 alloy per casting was used. Protective gas (volume fractions: $99.8 \% \mathrm{~N}_{2}+0.2 \% \mathrm{SF}_{6}$ ) was used during the whole experiment. Before the start of the experiment, a BN coating on the inner wall of the carbon-steel crucible and the casting mold was applied to prevent the adhesion of the molten metal, which facilitates the removal of the sample. The EV31 alloy was placed into a crucible, and the temperature was raised to $710^{\circ} \mathrm{C}$. After the alloy was completely melted, the dross on the surface of the melt was removed and the melt was kept at $710^{\circ} \mathrm{C}$ for $30 \mathrm{~min}$. The molten alloy was then poured into a "T-shaped" mold preheated to $270{ }^{\circ} \mathrm{C}$. At the same time, the alternating magnetic field was turned on until the molten metal in the mold was completely solidified and then the magnetic field was turned off. Each experiment was repeated at least three times to ensure both accuracy and repeatability. The temperature during the solidification of the alloy was recorded using a thermocouple, which was inserted at the hot spot of the "T"-shaped rod-casting connection area. The shrinkage force, which was generated during solidification, was measured with the sensor via a connecting rod at the end of the mold. The recorded analog signal was then transmitted to the analog-todigital converter (A/D), and the analog signal was converted into a digital signal using a signal-conversion module. The signal was then sent to the computer and displayed in the form of data and graphs.

Table 1: Chemical composition of alloys used in experiment (wt.\%)

\begin{tabular}{ccccccc} 
Element & Nd & Gd & Zn & Zr & Mg \\
\hline EV31 & 2.76 & 1.54 & 0.44 & 0.44 & Bal.
\end{tabular}

(a)
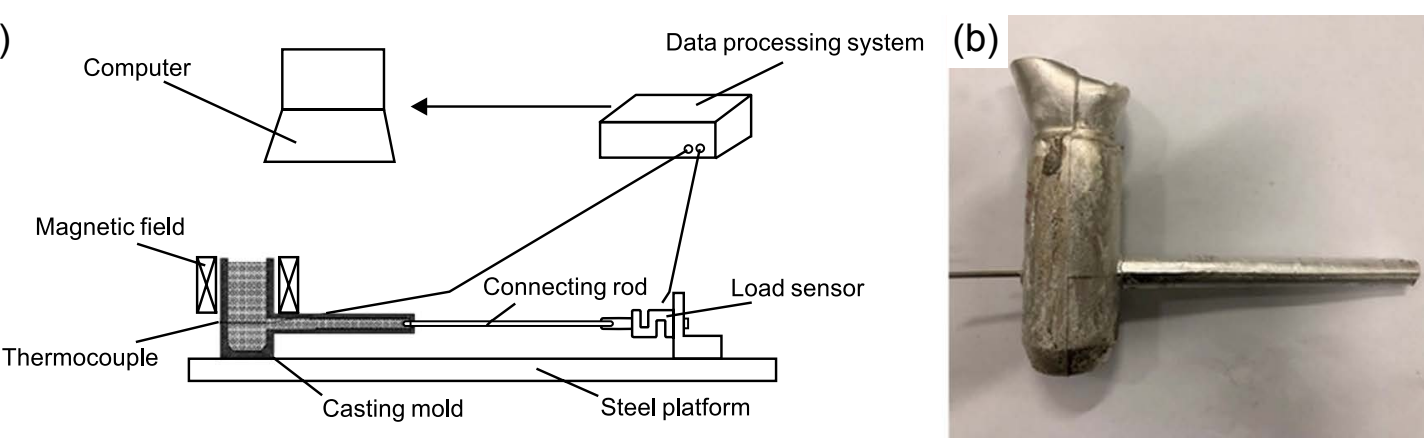

Fig. 1: Hot tearing measurement setup with an optional magnetic field (a) ${ }^{[12]}$ and hot tearing sample (b) 


\subsection{Differential thermal analysis system}

The solidification curve of the alloy was recorded and analyzed using the double galvanic thermal-analysis method, which made it possible to determine the dendrite coherency temperature $\left(T_{\text {coh }}\right)$. As shown in Fig. $2^{[12]}$, two thermocouples were placed at the center and edge of the crucible to measure the temperature at the center $\left(T_{\mathrm{c}}\right)$ and the temperature at the edge $\left(T_{\mathrm{e}}\right)$ of the alloy. To ensure the heat transfers in the crucible along the radial direction of the crucible, the top of the crucible was covered with a thicker asbestos net. The bottom was insulated with both thermal sand and asbestos.

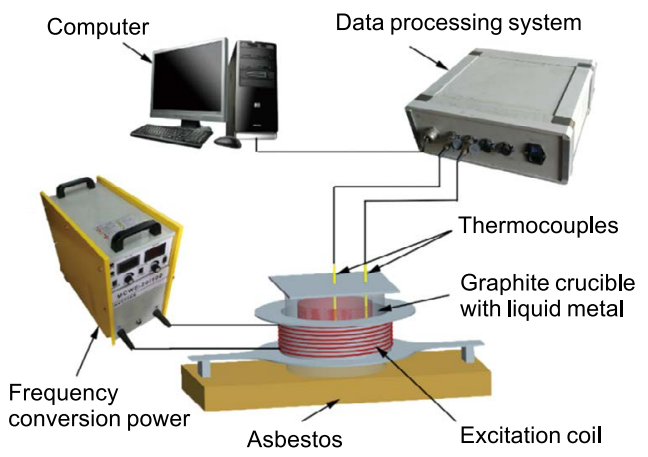

Fig. 2: Differential thermal analysis setup with a magnetic field $^{[12]}$

\subsection{Microscopic analysis}

The samples used for both microstructure and phase analysis were ground, polished and etched in a 4 vol.\% nitric acid alcohol solution for 2-5 s, and subsequently wiped with alcohol and dried. A Hitachi S-3400N scanning electron microscope (SEM) was used to observe the microstructure, fracture morphology and analyze the main hot crack-formation mechanism. In addition, combined with the AXIO-HAL-100 optical microscope (OM), the crack microstructure at the hot spot was observed and analyzed.

\subsection{Hot tearing susceptibility}

The prediction/calculation of the HTS of the alloy is based on the Clyne-Davies model ${ }^{[15,16]}$. According to the assumptions of the Clyne-Davies model, when the solid fraction $\left(f_{\mathrm{s}}\right)$ is between 0.4 and 0.9 , this period is called the force relaxation stage and expressed by $t_{\mathrm{R}}$. As the solidification process continues, when the solid fraction $\left(f_{\mathrm{s}}\right)$ is between 0.9 and 0.99 , this period is referred to as the fragile stage and denoted as $t_{\mathrm{V}}$.

The ratio of $t_{\mathrm{V}}$ to $t_{\mathrm{R}}$ is defined as the crack susceptibility coefficient (CSC), which is expressed by ${ }^{[17]}$ :

$$
\mathrm{CSC}=\frac{t_{\mathrm{V}}}{t_{\mathrm{R}}}=\frac{t_{0.99}-t_{0.9}}{t_{0.9}-t_{0.4}}
$$

where, $t_{0.99}$ is the time corresponding to the solid fraction 0.99 , $t_{0.9}$ denotes the time corresponding to the solid fraction 0.9 , and $t_{0.4}$ is the time corresponding to the solid fraction 0.4 .

\subsection{Numerical simulation parameters}

In this study, COMSOL was used to calculate both the velocity- field changes of the EV31 alloy during the solidification and the residual liquid-phase fraction under different alternating magnetic fields. In this experiment, the simulation conditions were as follows: the ambient temperature was $20^{\circ} \mathrm{C}$, the mold temperature was $270{ }^{\circ} \mathrm{C}$, the pouring temperature was $710{ }^{\circ} \mathrm{C}$, and the gravity acceleration during casting was $9.8 \mathrm{~m} \cdot \mathrm{s}^{-2}$. In the model, the magnetic field frequency was set to $10 \mathrm{~Hz}$, and the magnetic field currents were set to $0 \mathrm{~A}, 5 \mathrm{~A}, 10 \mathrm{~A}$, and $15 \mathrm{~A}$.

\section{Results and discussion}

\subsection{Numerical simulation results of liquid phase fraction of EV31 alloy}

Figures 3 and 4 show the magnetic flux density and the flow velocity, respectively. It can be seen from Fig. 3 that the magnetic flux is very large at the hot spot, and that forced convection occurs in metal melt under the action of magnetic field. Figure 4 confirms that convection occurs in different parts of the castings after the magnetic field is applied. Under the action of electromagnetic force, the alloy liquid forms an eddy current, the velocity field changes, and the alloy liquid is forced to convection. In other words, forced convection occurs in the molten metallic-pool, which facilitates the liquid flow of molten alloy during the solidification. A better filling ability helps reduce the HTS of the alloy.

The corresponding changes in liquid fraction at $10 \mathrm{~s}, 20 \mathrm{~s}$, and $40 \mathrm{~s}$ were measured. It can be seen from Fig. 5 that after the magnetic field is applied, the liquid fraction is higher than without applying the magnetic field at the same solidification time. Comparing Fig. 5(i-1), it can be found that when the solidification time is $40 \mathrm{~s}$, the corresponding liquid fractions at the hot spot of the castings under different alternating magnetic field strengths are $0.3,0.5,0.6$, and 0.7 , respectively. Clyne ${ }^{[15]}$ believed that when the liquid fraction was below 0.6 , feeding started. The high liquid fraction at the late stage of the solidification process facilitates the healing of hot cracks, which reduces the HTS of the alloy ${ }^{[13]}$. Therefore, according to the simulation results and literature, it can be seen that with the increase of magnetic field strength, the liquid fraction at the hot spot of the castings in the late solidification stage increases significantly, which is helpful to improve the feeding ability and reduce the HTS of the alloy.

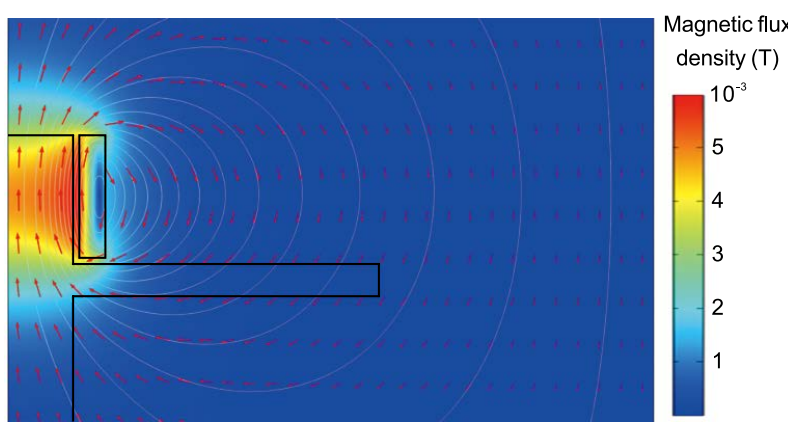

Fig. 3: Numerical simulation results of magnetic flux density contours 


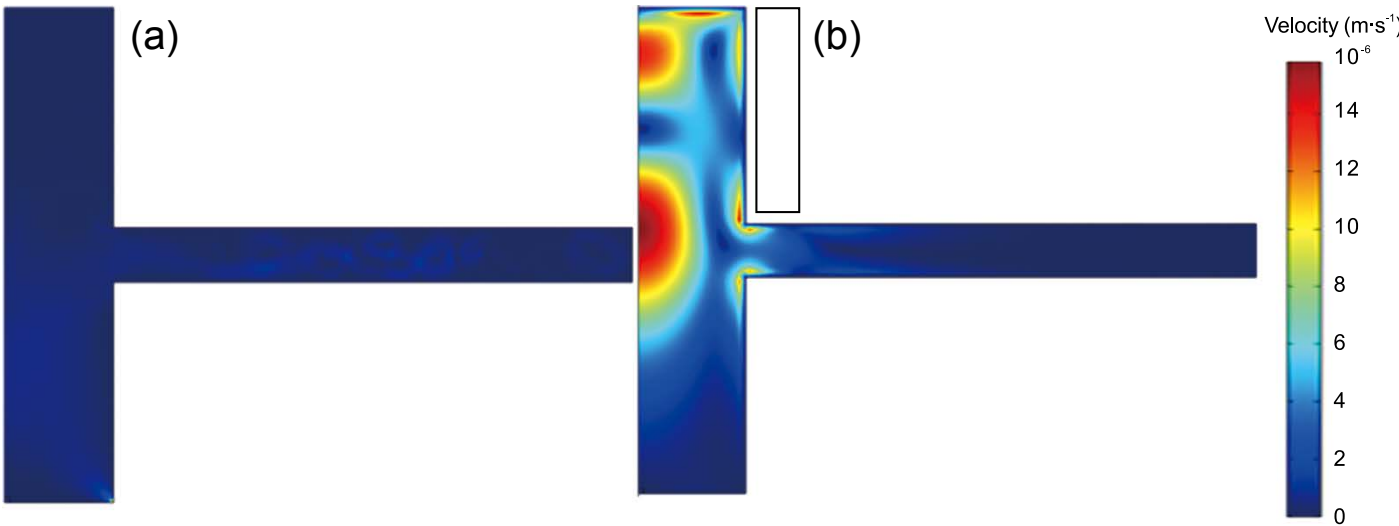

Fig. 4: Numerical simulation results for streamline profiles of velocity field: (a) $0 \mathrm{~A}, 0 \mathrm{~Hz}$ (b) $5 \mathrm{~A}, 10 \mathrm{~Hz}$

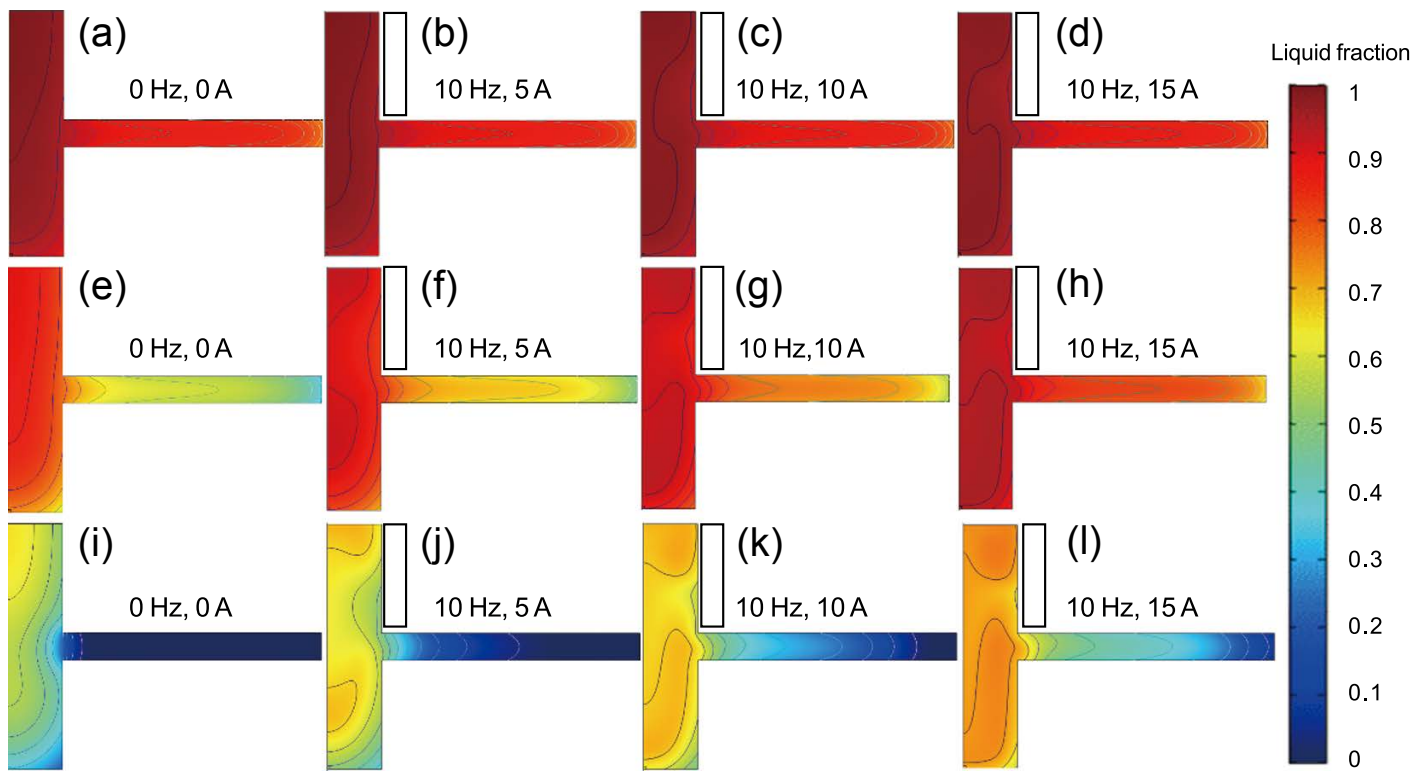

Fig. 5: Numerical simulation results for liquid fraction distribution under different solidification times: (a-d) EV31 alloy at 10 s; (e-h) EV31 alloy at 20 s; (i-I) EV31 alloy at 40 s

\subsection{Analysis of solidification behavior}

Figure 6 shows the cooling curve and its first derivative for EV31 with different magnetic field parameters. The baseline was determined using the Newton baseline method ${ }^{[6]}$. When the cooling curve has an inflection point and the temperature gradient shows a convex peak, latent crystallization heat is released, and a new phase precipitates within the liquid phase. The first derivative for Peak A marks the transition $\mathrm{L} \rightarrow \alpha-\mathrm{Mg}$, while Peak B signifies the $\mathrm{L} \rightarrow \alpha-\mathrm{Mg}+\mathrm{Mg}_{12} \mathrm{Nd}$ eutectic reaction ${ }^{[7]}$. After combining the cooling data of the alloy with the Clyne-Davies model [Eq. (1)], the CSC of the EV31 alloy for different magnetic field strengths can be calculated, as shown in Table 2. The alloy shows the highest HTS when no magnetic field is applied. When the magnetic field parameters are $10 \mathrm{~Hz} 15 \mathrm{~A}$, the alloy shows the lowest HTS, and the HTS of the alloy decreases with increasing magnetic field strength.

\subsection{Dendrite coherency temperature}

Several research groups ${ }^{[18-20]}$ defined the area where the solidphase volume fraction is between 0.9 and 0.99 as the "fragile interval" of the alloy, and the corresponding temperature interval is denoted as $\Delta T_{\mathrm{c}}$. During this interval, there are many solid phases and less of the residual liquid phase. This means the degree of solidification shrinkage is high but the amount of residual liquid phase, which can be used for feeding, is small. Furthermore, the greater the temperature interval $\Delta T_{\mathrm{c}}$ in the fragile zone, the greater the hot cracking tendency. Table 3 shows both the solidification temperature interval $\left(\Delta T_{1-\mathrm{s}}\right)$ for each magnetic field parameter set and the measured temperature interval $\Delta T_{\mathrm{c}}$ of the fragile area. The minimum $\Delta T_{\mathrm{c}}$ of EV31 is $30.7^{\circ} \mathrm{C}$ and occurs when the magnetic field current is $15 \mathrm{~A}$. The maximum $\Delta T_{\mathrm{c}}$ of EV31 is $68.6^{\circ} \mathrm{C}$ without a magnetic field. This indicates that the hot cracking tendency of the EV31 alloy gradually decreases with increasing magnetic field strength, which is consistent with the trend of the CSC results (shown in Table 2).

During the solidification process, the solidification fraction in the crucible increases as the temperature decreases, due to the heat conductivity of the solid phase being greater than that of the liquid phase. When dendritic coherence occurs 

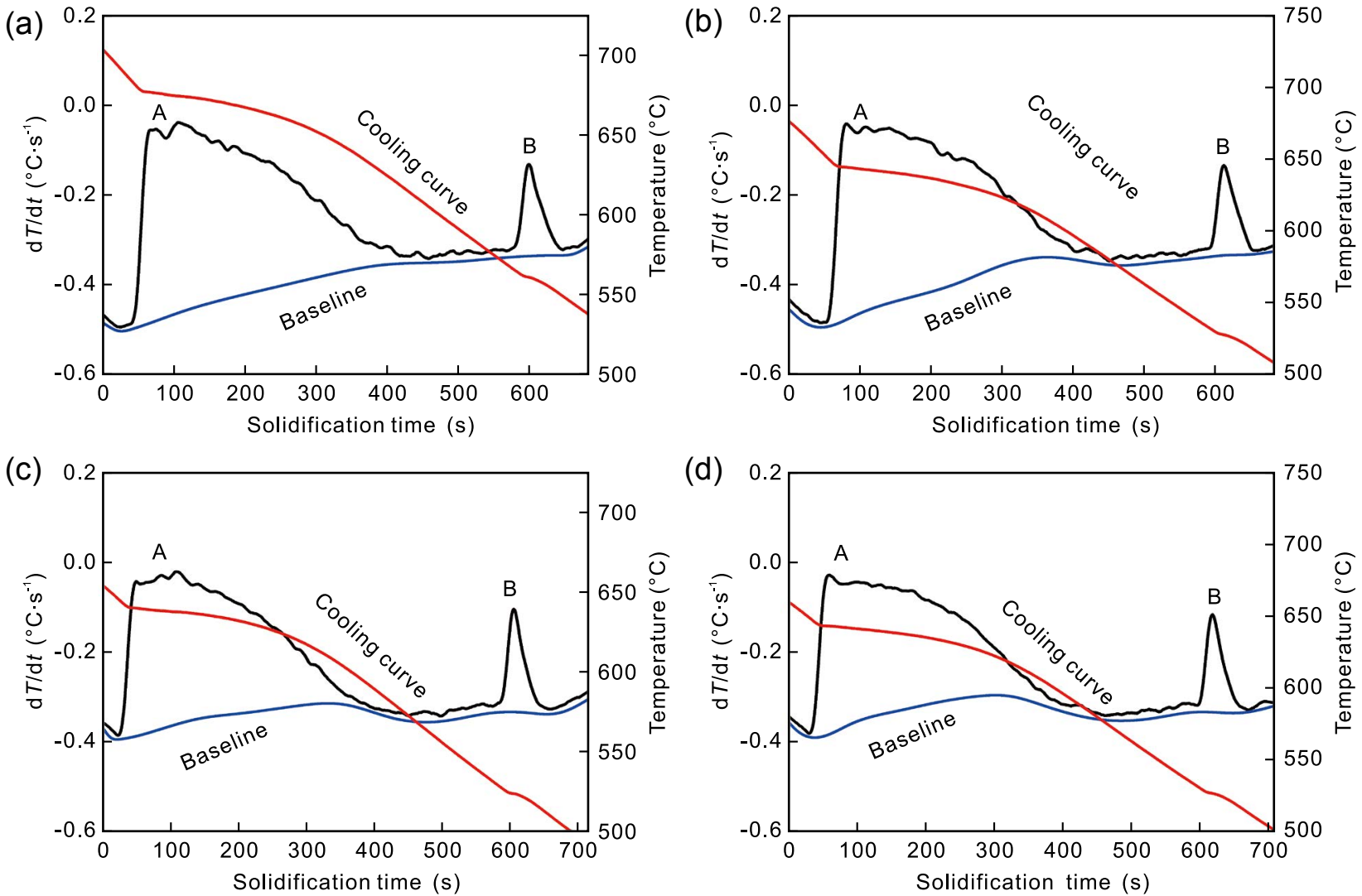

Fig. 6: Thermal analysis curves of EV31 alloy with different magnetic field parameters: (a) 0 A, $0 \mathrm{~Hz}$; (b) $5 \mathrm{~A}, 10 \mathrm{~Hz}$; (c) $10 \mathrm{~A}, 10 \mathrm{~Hz}$; (d) $15 \mathrm{~A}, 10 \mathrm{~Hz}$

Table 2: CSC of EV31 alloy with different magnetic field parameters

\begin{tabular}{rllll} 
Magnetic field & $\boldsymbol{t}_{0.4}(\mathbf{s})$ & $\boldsymbol{t}_{0.9}(\mathbf{s})$ & $\boldsymbol{t}_{0.99}(\mathbf{s})$ & CSC \\
\hline $0 \mathrm{~Hz}$, 0 A & 192.2 & 504.2 & 629.0 & 0.400 \\
$10 \mathrm{~Hz}$, 5 A & 160.5 & 510.5 & 639.2 & 0.368 \\
$10 \mathrm{~Hz}, 10 \mathrm{~A}$ & 135.8 & 543.8 & 663.9 & 0.294 \\
$10 \mathrm{~Hz}, 15 \mathrm{~A}$ & 142.5 & 534.6 & 646.5 & 0.285
\end{tabular}

Table 3: $\Delta T_{\mathrm{c}}, \Delta T_{\mathrm{l}-\mathrm{s}}$ and $T_{\text {coh }}$ values with different magnetic field parameters

\begin{tabular}{rccc} 
Magnetic field & $\Delta T_{\mathrm{c}}\left({ }^{\circ} \mathrm{C}\right)$ & $\Delta T_{\text {l-s }}\left({ }^{\circ} \mathrm{C}\right)$ & $T_{\text {coh }}\left({ }^{\circ} \mathrm{C}\right)$ \\
\hline 0 Hz, 0 A & 68.6 & 126.1 & 642.5 \\
$10 \mathrm{~Hz}$, 5 A & 40.8 & 118.5 & 631.3 \\
$10 \mathrm{~Hz}$, 10 A & 38.0 & 116.0 & 625.6 \\
$10 \mathrm{~Hz}$, 15 A & 30.7 & 115.5 & 618.4
\end{tabular}

during solidification, the heat transfer accelerates, and the temperature difference between the edge and center of crucible $\left(\Delta T, \Delta T=T_{\mathrm{e}}-T_{\mathrm{c}}\right.$ ) will have a minimum value. The temperature at this point is defined as the dendritic coherence temperature $\left(T_{\text {coh }}\right)$, and the corresponding solid fraction is defined as the dendritic coherence solid fraction ${ }^{[21-24]}$. Figure $7(a)$ illustrates the calculation method for the dendrite coherency temperature. Figure 7(b) shows the dendrite coherency temperature of the EV31 alloy, which is summed in Table 3 . The highest $T_{\text {coh }}$ is
$642.5{ }^{\circ} \mathrm{C}$ when there is no magnetic field, while the $T_{\text {coh }}$ of the alloy is the lowest $\left(618.4^{\circ} \mathrm{C}\right)$ when the magnetic field parameters are $10 \mathrm{~Hz}$ and $15 \mathrm{~A}$. The higher the dendrite coherence temperature of the alloy, the earlier the $\alpha-\mathrm{Mg}$ phase is formed, and the dendrites start to overlap at a higher temperature. This makes it difficult to feed the residual liquid phase and therefore, increase the HTS of the alloy. Overall, with the increase of magnetic field strength, the dendrite coherency temperature of the alloy decreases, and the HTS of the alloy also decreases. 
(a)

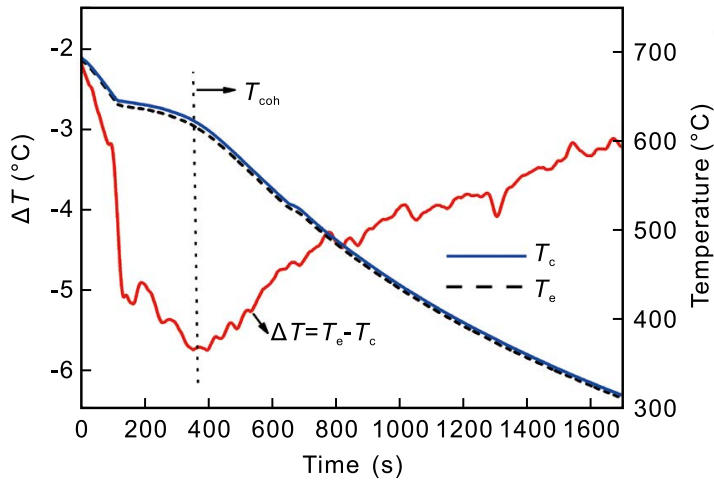

(b)

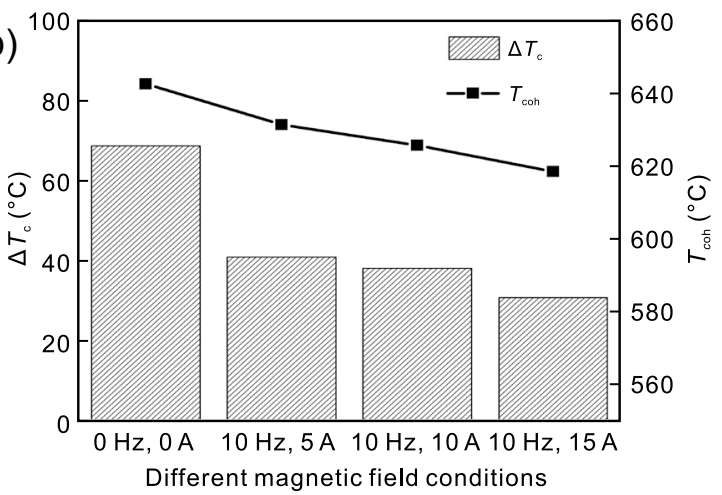

Fig. 7: Calculation method for dendrite coherency temperature (a), and dendrite coherency temperature (b) of EV31 alloy with different magnetic field parameters

\subsection{Microstructure analysis}

Figure 8 shows the microstructure images of EV31 alloy with different alternating magnetic field parameters. The EV31 magnesium alloy mainly consists of the $\mathrm{Mg}_{12} \mathrm{Nd}$ eutectic phase and $\alpha-\mathrm{Mg}$ matrix. The solidified structure of the EV31 magnesium alloy, when treated by the alternating magnetic field, is more refined than the untreated solidified structure. Electromagnetic force produced by the alternating magnetic field will break coarse dendrites during metal solidification, prevent dendrites from growing, and reduce alloy grain size ${ }^{[25,26]}$.
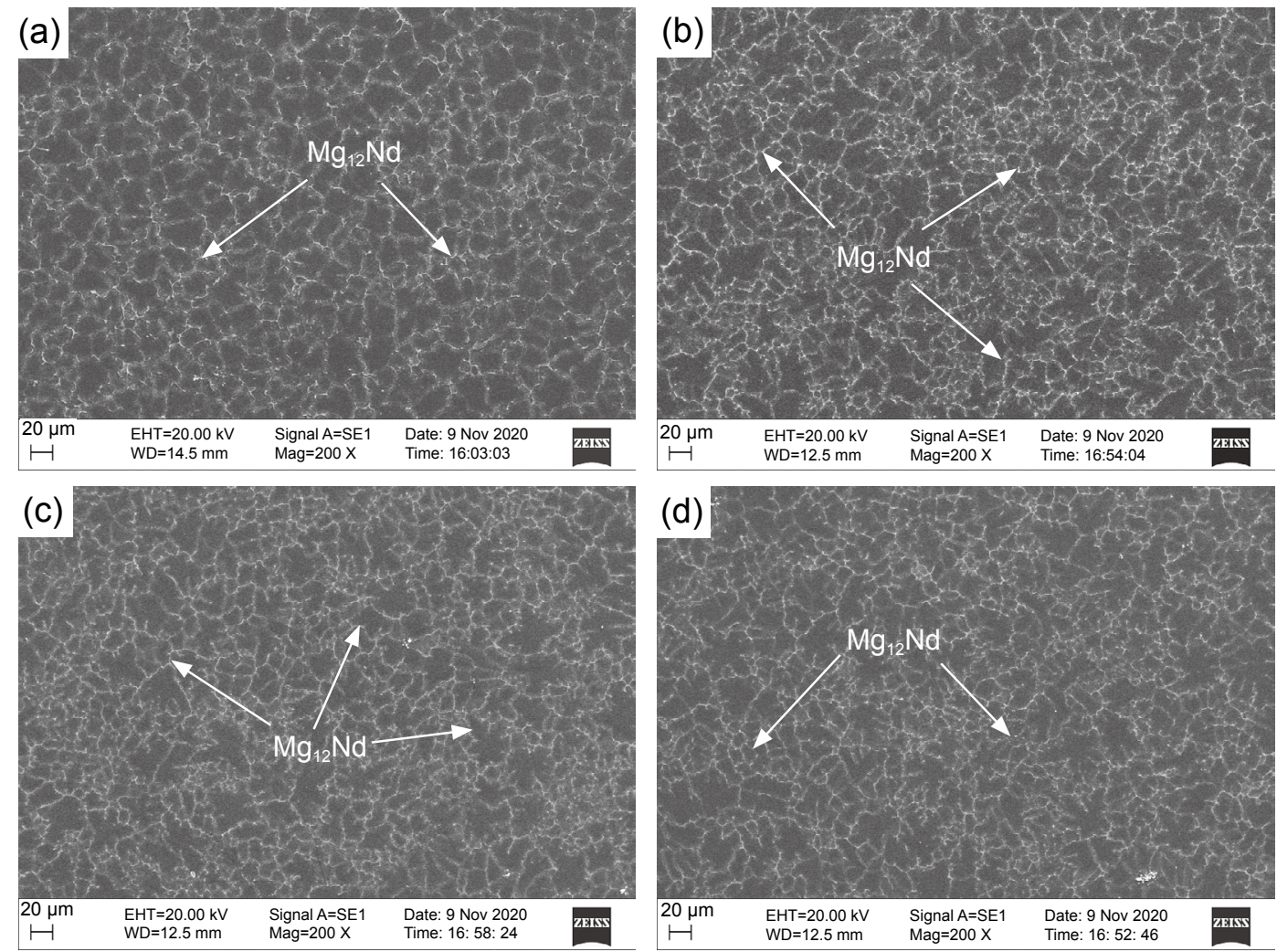

Fig. 8: Microstructure of EV31 alloy with different magnetic-field parameters: (a) $0 \mathrm{~A}, 0 \mathrm{~Hz}$; (b) $5 \mathrm{~A}, 10 \mathrm{~Hz}$; (c) $10 \mathrm{~A}, 10 \mathrm{~Hz}$; (d) $15 \mathrm{~A}, 10 \mathrm{~Hz}$

\subsection{Hot tearing behavior}

Figure 9 shows the shrinkage force and temperature changes of the EV31 alloy as a function of solidification time with different magnetic field strengths. During the early stage of solidification, the solid fraction is low, the dendrites do not overlap. Therefore, shrinkage force value at this time range is 0 . As the alloy continues to solidify, the alloy's shrinkage force begins to increase significantly. When the force at the hot node of the "T" shaped sample exceeds the fracture strength of the alloy, the hot cracks can start to develop and expand. Moreover, force relaxation is visible in the time/force curve (i.e., force suddenly drops). It can be seen from Fig. 9 that, under the influence of an alternating magnetic field, as the magnetic field strength increases gradually, the load curve gradually becomes smoother. As shown in Fig. 9(a), there is a sharp fluctuation in the load curve (near the two dashed lines 
in Fig. 9). This indicates that large cracks occurred. Combined with the SEM images (Fig. 8), it can be concluded that coarse grains are the main reason for the high HTS of EV31 alloy. Figure 9(b) reveals a slight drop, which shows that hot tearing occurred during this process. However, due to the weaker magnetic field, the refinement effect is insufficient, and fracture occurs eventually. With the increase of the magnetic field intensity, the grain refinement effect becomes more obvious, and the load curve does not appear to drop significantly. This indicates that there is no obvious hot cracking in the casting, and the alloy shows the low HTS [as shown in Fig. 9(c-d)]. On the one hand, grain refinement can increase the surface area of a liquid film, better resist tearing by solidificationshrinkage force, and reduce the HTS of the alloy. Furthermore, alloys with fine grains can more easily adapt to local strains in small areas and are less prone to hot cracks.

Figure 10 shows macroscopic crack photographs at the spots of the EV31 magnesium alloy under different magnetic field conditions. The crack volume clearly decreases with increasing magnetic field strength. The increase in magnetic field strength promotes the flow of residual liquid between dendrites, improves the feeding efficiency of residual liquid, and thereby reduces the HTS of the alloy. Herein, under the influence of a $10 \mathrm{~Hz} 15 \mathrm{~A}$ alternating magnetic field, the alloy shows the highest hot tearing resistance. With the increase of the magnetic field intensity, the microstructure of the alloy is continuously refined and the feeding ability of the alloy is enhanced, which makes it show the low HTS. This is consistent with the simulation results. (a)

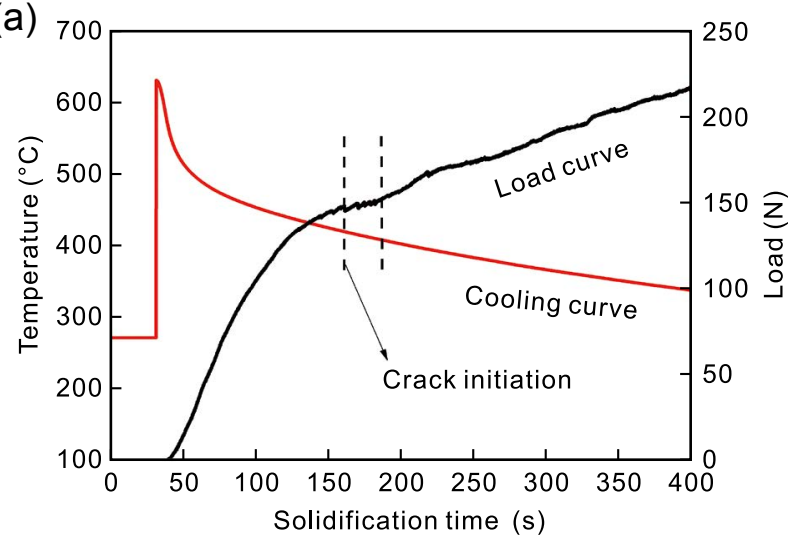

(c)

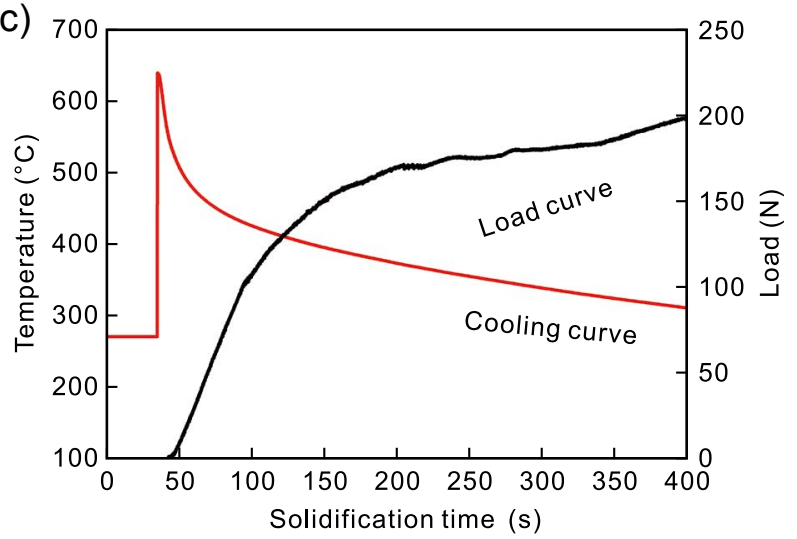

(b)

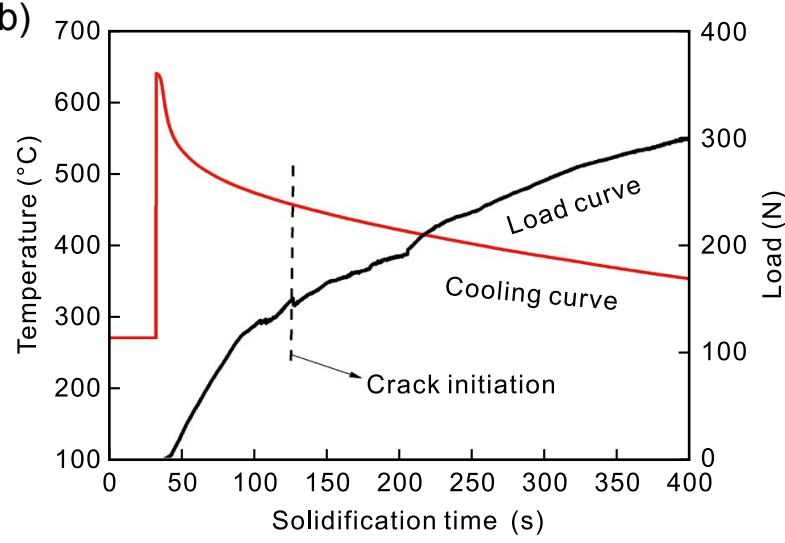

(d)

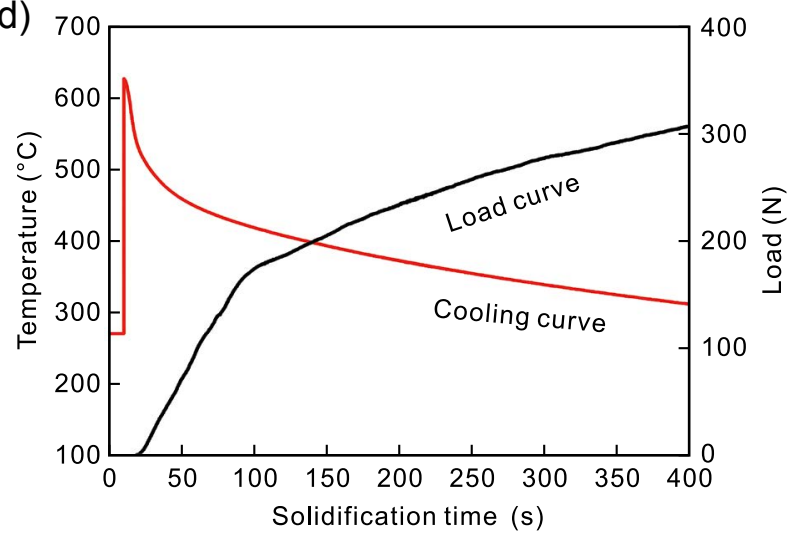

Fig. 9: Hot tearing curves of EV31 alloy with different magnetic field parameters: (a) $0 \mathrm{~A}, 0 \mathrm{~Hz}$; (b) $5 \mathrm{~A}, 10 \mathrm{~Hz}$; (c) $10 \mathrm{~A}, 10 \mathrm{~Hz}$; (d) $15 \mathrm{~A}, 10 \mathrm{~Hz}$
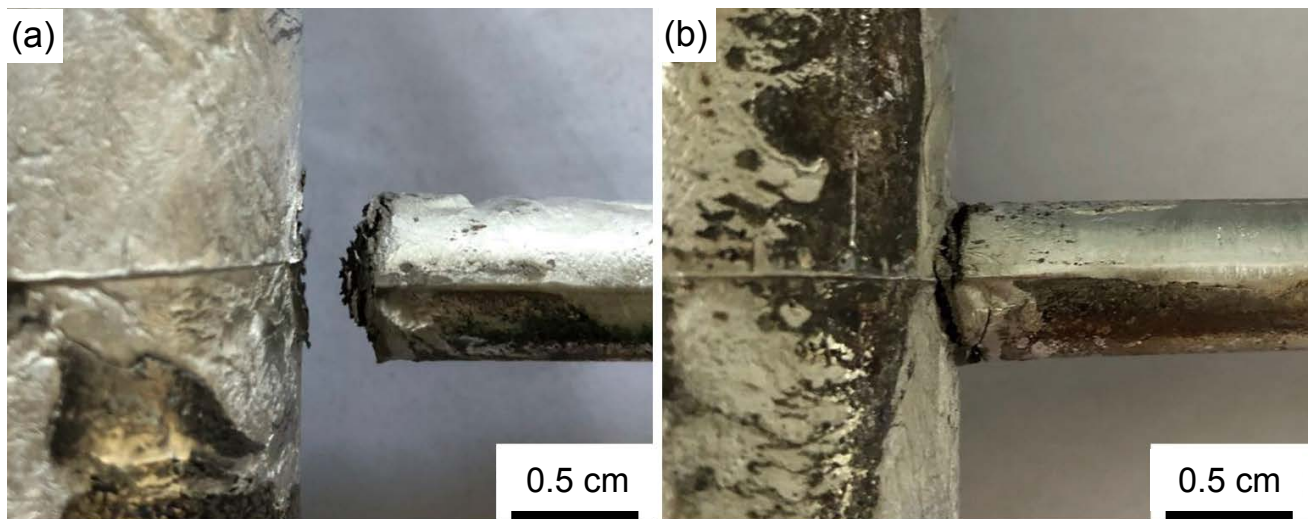

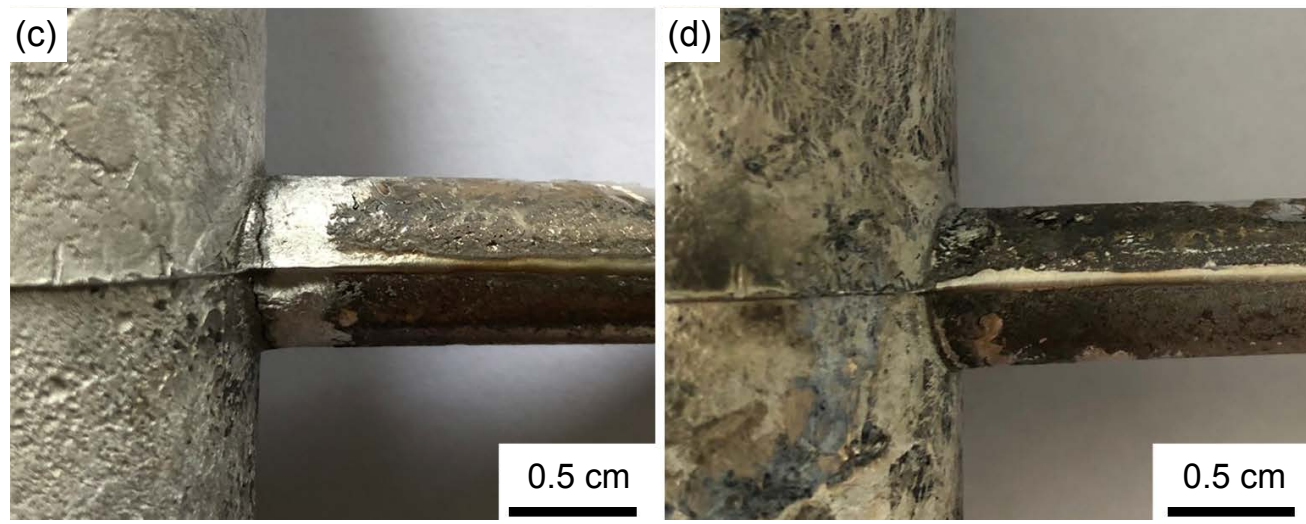

Fig. 10: Macroscopic crack photographs of EV31 alloy with different magnetic fields parameters: (a) $0 \mathrm{~A}, 0 \mathrm{~Hz}$ (b) $5 \mathrm{~A}, 10 \mathrm{~Hz}$; (c) $10 \mathrm{~A}, 10 \mathrm{~Hz}$; (d) $15 \mathrm{~A}, 10 \mathrm{~Hz}$

\subsection{Fracture morphology}

Due to the chemically active nature of $\mathrm{Mg}$, it is easy to produce oxidized slag during the melting process, which affects both the fluidity of the alloy and the quality of the castings. The main reason for the effect of oxides on the HTS of the alloy is the fluidity of the liquid alloy. An important factor that determines the fluidity of a liquid alloy is the number of inclusions in the alloy as well as the physical properties of these inclusions. Because magnesium alloy is easily oxidized, there are many non-metallic inclusions in the alloy liquid prior to purification. These inclusions reduce the fluidity of the alloy substantially, which affects the alloy's HTS ${ }^{[27,28]}$. With the addition of the magnetic field, the inclusions are controlled effectively. It can be seen from Fig. 11(c) that few inclusions are located near the crack. When the magnetic field condition is $15 \mathrm{~A} 10 \mathrm{~Hz}$, no inclusions appear near the cracks of the casting, as shown in Fig. 11(d). As shown in Fig. 12, based on the EDS analysis, the inclusions may consist of a mix of $\mathrm{MgO}$ and $\mathrm{Mg}_{12} \mathrm{Nd}$. This oxide can cause the matrix to tear and prevent the residual liquid phase from feeding at the end of the solidification, which can lead to hot tearing of the alloy ${ }^{[29-31]}$. At the same time, when the magnetic field continues to increase, the crystal grains continue to be refined (Fig. 8). Using both Fig. 11(d) and Fig. 12(b), it can be found that the melt is purified after the magnetic field treatment, and the second phase precipitated. Furthermore, the
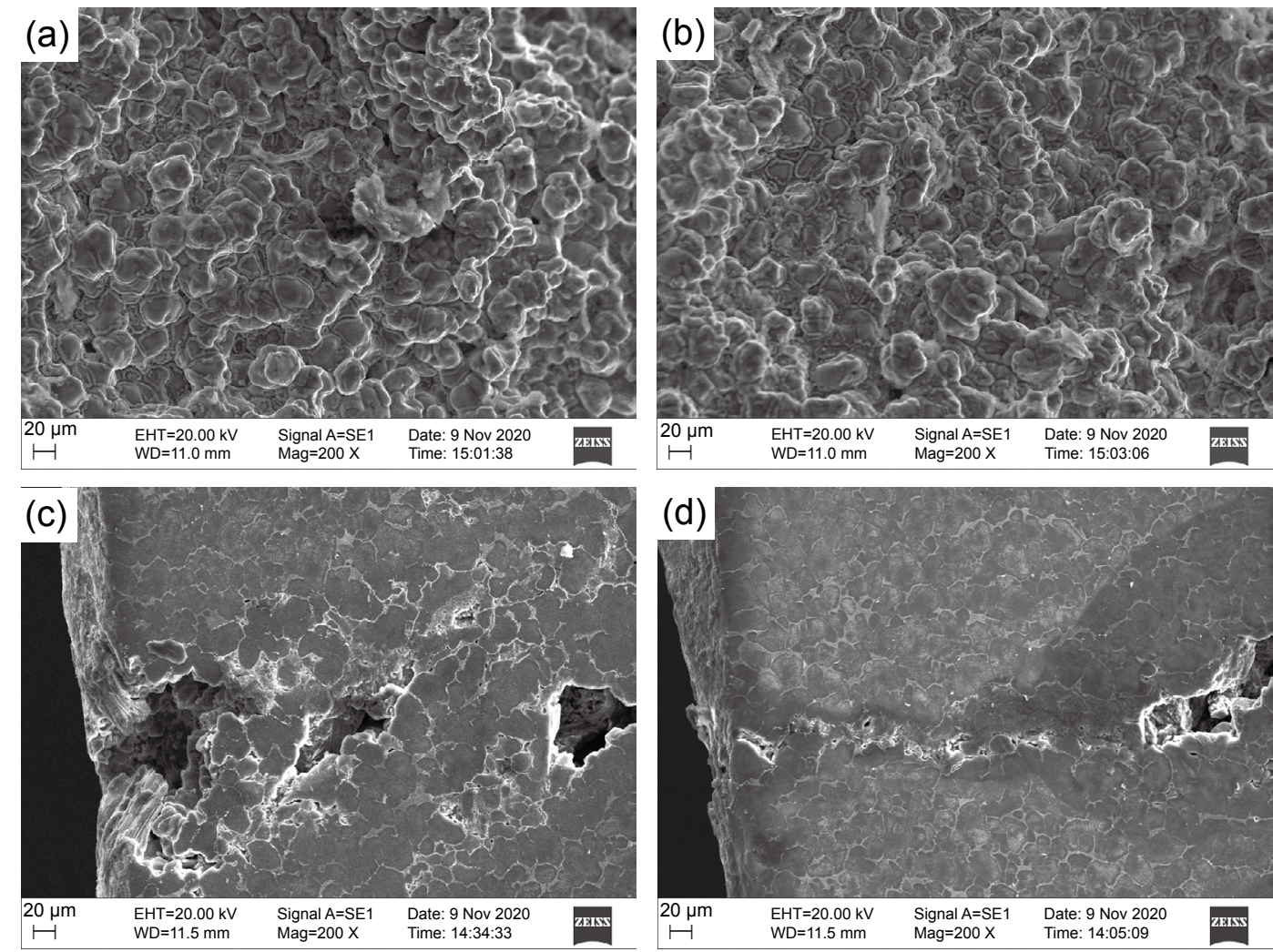

Fig. 11: Morphology of fracture surface of EV31 alloy with different magnetic field parameters: (a) $0 \mathrm{~A}, 0 \mathrm{~Hz}$; (b) $5 \mathrm{~A}, 10 \mathrm{~Hz}$; (c) $10 \mathrm{~A}, 10 \mathrm{~Hz}$; (d) $15 \mathrm{~A}, 10 \mathrm{~Hz}$ 

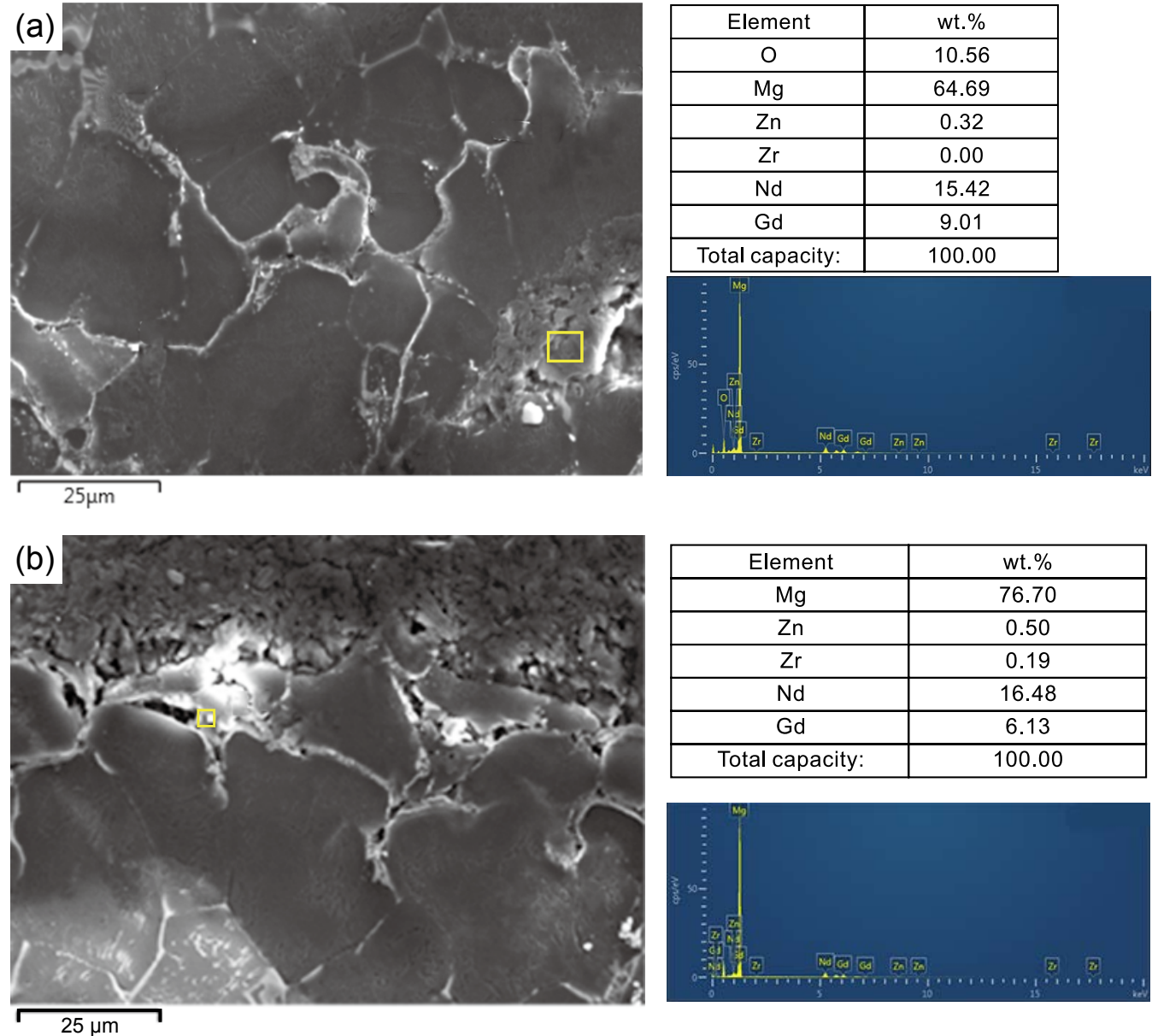

\begin{tabular}{|c|c|}
\hline Element & wt.\% \\
\hline $\mathrm{Mg}$ & 76.70 \\
\hline $\mathrm{Zn}$ & 0.50 \\
\hline $\mathrm{Zr}$ & 0.19 \\
\hline $\mathrm{Nd}$ & 16.48 \\
\hline $\mathrm{Gd}$ & 6.13 \\
\hline Total capacity: & 100.00 \\
\hline
\end{tabular}

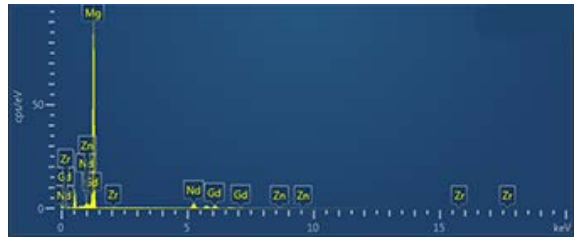

Fig. 12: EDS analysis of EV31 alloy with different magnetic field parameters: (a) $10 \mathrm{~A}, 10 \mathrm{~Hz}$; (b) $15 \mathrm{~A}, 10 \mathrm{~Hz}$

oxygen content is reduced, the $\mathrm{MgO}$ impurities disappear, and the feeding effect of $\mathrm{Mg}_{12} \mathrm{Nd}$ is strengthened. This can also greatly reduce the HTS of the alloy. Based on the test results for this alloy, it can be concluded that increasing the magnetic field strength can purify the melt and improve feeding ability, which reduce the alloy's HTS.

\section{Conclusions}

(1) The predicted (simulated) value of EV31 alloy's hot tearing susceptibility (HTS) is consistent with the experimental results. The HTS of EV31 is found to decrease gradually with increasing the magnetic field strength. Furthermore, EV31 has the lowest HTS when the alternating magnetic field parameters are $10 \mathrm{~Hz}, 15 \mathrm{~A}$.

(2) With increasing magnetic field strength, the melt becomes more purified, and the number of slag inclusions in the melt decreases. This increases the alloy's resistance to hot tearing significantly.

(3) The alternating magnetic field can increase the forced convection of the melt, break the dendrites, refine the grains, and reduce the alloy's dendrite coherency temperature. This enhances the flow of residual liquid during the later stage of solidification, improves the feeding ability, and reduces the HTS of the alloy.

\section{Acknowledgements}

This work was financially supported by the Joint Research Fund Liaoning-Shenyang National Laboratory for Materials Science (2019JH3/30100014) and the Innovation Talent Program in Science and Technologies for Young Middleaged Scientists of Shengyang (RC200414).

\section{References}

[1] Fu S L, Li Q A, Jing X T, et al. The effect of heat treatment on the microstructure of $\mathrm{Mg}-12 \mathrm{Gd}-2 \mathrm{Y}-0.5 \mathrm{Sm}-0.5 \mathrm{Sb}-0.5 \mathrm{Zr}$. Transactions of Materials and Heat Treatment, 2014, 35(4): 46-50. (In Chinese)

[2] Yang M B, Pan F S, Tang A T, et al. Research status of Mg$\mathrm{Zn}-\mathrm{Al}(\mathrm{ZA})$ series heat-resistant magnesium alloys. Metal Hotworking, 2007, 36(8): 73-77. (In Chinese)

[3] Chen X Q, Liu J W, Luo C P, et al. Research status and development trend of high strength $\mathrm{Mg}-\mathrm{Zn}$ series alloys. Materials Review, 2008, 22(5): 58-62. (In Chinese)

[4] Dahle A K, Lee Y C, Nave M D, et al. Development of the ascast microstructure in magnesium-aluminium alloys. Journal of Light Metals, 2001, 1(1): 61-72.

[5] Wang Y S, Sun B D, Wang Q D, et al. An understanding of the hot tearing mechanism in AZ91 magnesium alloy. Materials Letters, 2002, 53(1-2): 35-39.

[6] Zhou Z J, Liu Z, Wang Y, et al. Effects of the second phase on hot tearing susceptibility of $\mathrm{Mg}-\mathrm{Zn}-\mathrm{Y}$ alloy. Materials Research Express, 2018, 6(1): 016529. 
[7] Zheng $K Y$, Zeng $X Q$, Dong J, et al. Effect of initial temperature on the creep behavior of a Mg-Gd-Nd-Zr alloy. Materials Science and Engineering A, 2008, 492(1-2): 185-190.

[8] Zheng $K Y$, Dong J, Zeng $X$ Q, et al. Effect of pre-deformation on aging characteristics and mechanical properties of a MgGd-Nd-Zr alloy. Materials Science and Engineering A, 2008, 491(1-2): 103-109.

[9] Guo S J, Le Q C, Zhao Z H, et al. Microstructure character of AZ80 magnesium alloy ingots cast under electromagnetic vibration. China Foundry, 2007, 4(1): 22-25.

[10] El-Kaddah N, Patel A D, Natarajan T T. The electromagnetic filtration of molten aluminum using an induced-current separator. Journal of Metals, 1995, 47(5): 46-49.

[11] Li Y H, Xu G M, Cui J Z. Purification of magnesium alloy melt under electromagnetic field. Light Alloy Fabrication Technology, 2008, 36(7): 19-22. (In Chinese)

[12] Du X D, Wang F, Wang Z, et al. Hot tearing susceptibility of AXJ530 alloy under low-frequency alternating magnetic field. Acta Metallurgica Sinica (English Letters), 2020, 33(9): 1259-1270.

[13] Zhou Y, Mao P, Wang Z, et al. Effect of low frequency alternating magnetic field on hot tearing susceptibility of Mg-7Zn-1Cu-0.6Zr magnesium alloy. Journal of Materials Processing Technology, 2020, 282: 116679.

[14] Zhang Z Q, Le Q C, Bao L, et al. Effects of low frequency electromagnetic field on surface quality, microstructure and hot-tearing tendency of semi-continuous casting ZK60 magnesium alloy billets. China Foundry, 2013, 10(6): 351-354.

[15] Dahle A K, Lee Y C, Nave M D, et al. Development of the ascast microstructure in magnesium-aluminum alloys. Journal of Light Metals, 2001, 1(1): 61-72.

[16] Clyne T W, Davies G J. Volume contractions accompanying solidification of aluminium-copper alloys. Journal of Materials Science \& Technology, 1978, 12(5): 233-238.

[17] Dong H K, Wang F, Wang Z, et al. Effect of Sn addition on hot tearing susceptibility of AXJ530 alloy. Materials Research Express, 2018, 5(3): 036513.

[18] Wang B, Liu Z, Mao P L, et al. Hot tearing susceptibility of MgAl-Ca alloy with different $\mathrm{Sn}$ additions. Chinese Journal of Rare Metals, 2016, 244(7): 647-653. (In Chinese)

[19] Liu Z, Zhang S B, Mao $P$ L, et al. Effects of $Y$ on hot tearing susceptibility of $\mathrm{Mg}-\mathrm{Zn}-\mathrm{Y}-\mathrm{Zr}$ alloys. Transactions of Nonferrous Metals Society of China, 2014, 24(4): 907-914.
[20] Zhou Y, Mao P L, Wang Z, et al. Effects of copper content and mold temperature on the hot tearing susceptibility of $\mathrm{Mg}-7 \mathrm{Zn}$ $x \mathrm{Cu}-0.6 \mathrm{Zr}$ alloys. Metallurgical and Materials Transactions $\mathrm{B}$, 2018, 49(6): 3444-3455.

[21] Miao $L$ L, Zhang $X$, Zhang $K$, et al. Effect of $Y$ on microstructure and properties of as-cast Mg-Y alloy. Special Casting \& Nonferrous Alloys, 2015, 35(6): 636-640. (In Chinese)

[22] Wang Z, Li Y, Wang F, et al. Effect of $\mathrm{Cu}$ additions on microstructure, mechanical properties and hot-tearing susceptibility of $\mathrm{Mg}-6 \mathrm{Zn}-0.6 \mathrm{Zr}$ alloys. Journal of Materials Engineering \& Performance, 2016, 25(12): 5530-5539.

[23] Luo $S$ Q, Tang A T, Pan F S, et al. Effect of mole ratio of $Y$ to $\mathrm{Zn}$ on phase constituent of Mg-Zn-Zr-Y alloys. Transactions of Nonferrous Metals Society of China, 2011, 21(4): 795-800.

[24] Mao P L, Qin J M, Liu Z, et al. Hot tearing susceptibility of EW75 magnesium alloy. Transactions of Materials and Heat Treatment, 2016, 37(6): 55-60.

[25] Muraji M, Nishimura M, Tatebe W, et al. Effect of alternating magnetic field on the growth of the primary root of corn. IEEE Transactions on Magnetics, 1992, 32(4): 1996-2000.

[26] Fu J W, Yang Y S. Microstructure and mechanical properties of Mg-Al-Zn alloy under a low-voltage pulsed magnetic field. Materials Letters, 2012, 67(1): 252-255.

[27] Liu Y Z, Zhan L H, Ma Q Q, et al. Effects of alternating magnetic field aged on microstructure and mechanical properties of AA2219 aluminum alloy. Journal of Alloys and Compounds, 2015, 647: 644-647.

[28] Guo S J, Cui J Z, Le Q C, et al. The effect of alternating magnetic field on the process of semi-continuous casting for AZ91 billets. Materials Letters, 2005, 59(14-15): 1841-1844.

[29] Wang Z, Huang Y D, Srinivasan A, et al. Experimental and numerical analysis of hot tearing susceptibility for Mg-Y alloys. Journal of Materials Science, 2014, 49(1): 353-362.

[30] Wang Z, Huang Y D, Srinivasan A, et al. Hot tearing susceptibility of binary $\mathrm{Mg}-\mathrm{Y}$ alloy castings. Materials \& Design, 2013, 47: 90-100.

[31] Zhu G N, Wang Z, Qiu W. et al. Effect of yttrium on hot tearing susceptibility of $\mathrm{Mg}-6 \mathrm{Zn}-1 \mathrm{Cu}-0.6 \mathrm{Zr}$ alloys. International Journal of Metalcasting, 2020, 14: 179-190. 